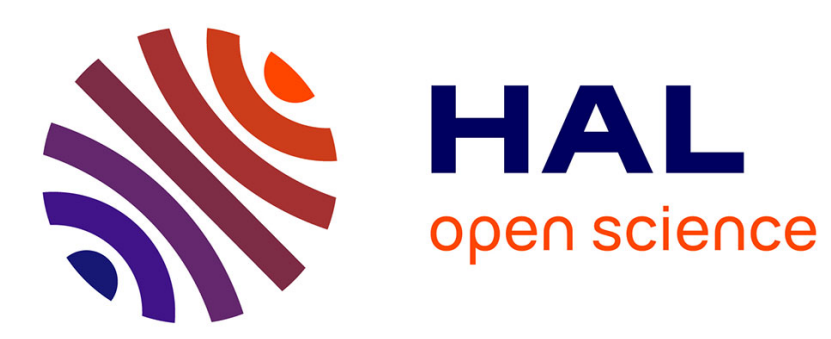

\title{
Ductile - Brittle Transition of Ferritic Steels Modelled by the Local Approach to Fracture
}

S. Renevey, S. Carassou, Bernard Marini, C. Eripret, André Pineau

\section{To cite this version:}

S. Renevey, S. Carassou, Bernard Marini, C. Eripret, André Pineau. Ductile - Brittle Transition of Ferritic Steels Modelled by the Local Approach to Fracture. Journal de Physique IV Proceedings, 1996, 06 (C6), pp.C6-343-C6-352. 10.1051/jp4:1996634 . jpa-00254462

\section{HAL Id: jpa-00254462 https://hal.science/jpa-00254462}

Submitted on 1 Jan 1996

HAL is a multi-disciplinary open access archive for the deposit and dissemination of scientific research documents, whether they are published or not. The documents may come from teaching and research institutions in France or abroad, or from public or private research centers.
L'archive ouverte pluridisciplinaire HAL, est destinée au dépôt et à la diffusion de documents scientifiques de niveau recherche, publiés ou non, émanant des établissements d'enseignement et de recherche français ou étrangers, des laboratoires publics ou privés. 


\title{
Ductile - Brittle Transition of Ferritic Steels Modelled by the Local Approach to Fracture
}

\author{
S. Renevey, S. Carassou, B. Marini, C. Eripret* and A. Pineau** \\ CEA, CEREM/SRMA, CEA/Saclay, 91191 Gif-sur-Yvette cedex, France \\ * EDF, DER Centre de Recherche Les Renardières, 77250 Moret-sur-Loing, France \\ ** Centre des Matériaux, Ecole des Mines de Paris, URA 866 du CNRS, BP. 87, 91003 Evry cedex, \\ France
}

\begin{abstract}
Tensile tests on axisymmetrically notched specimens were performed at various temperatures in the ductile-brittle transition region to study the initiation of fracture. Fracture toughness tests on CT specimens were also carried out in the same region to investigate the critical values of stable crack growth occurring before unstable cleavage fracture. Probabilistic modelling is made by coupling the Beremin model for cleavage crack initiation and a model derived from the Gurson potential. In an elementary volume the probability for fracture depends on the probability of both modes of failure. In a larger volume the probability to fracture is expressed in terms of elementary probabilities of fracture through the weakest link theory. Modelling is applied to axisymmetrically notched bars and to CT specimens. The analysis of results shows that the ductile-brittle transition of ferritic steels can be interpreted quantitatively as a competition between both types of damage.
\end{abstract}

\section{INTRODUCTION}

It is well known that cleavage fracture can be preceded by ductile crack extension when low alloy ferritic steels are tested in the ductile-brittle transition. In this region of temperature, the measured material toughness presents a wide scatter and is strongly dependent on temperature.

Two assumptions are usually made to model this behaviour. First, it can be assumed that both modes of failure are in competition. One given fracture mode is initiated prior to the other one when its mechanical and metallurgical condition is reached. It can also be assumed that the two fracture modes are interacting; the ductile damage modifying the conditions for the brittle fracture initiation.

In this work, an attempt is made to show that the results obtained on a low alloy steel tested in the transition regime can be interpreted mainly by the assumption of the competition process which becomes quantitative through the use of the local approach to fracture.

\section{MATERIAL AND EXPERIMENTAL PROCEDURES}

The material was taken from a PWR nozzle cut-out. The composition was, in weight percent : $\mathrm{C}=0.16$, $\mathrm{Mn}=1.38, \mathrm{Ni}=0.70, \mathrm{Mo}=0.50, \mathrm{Si}=0.24, \mathrm{Cr}=0.17, \mathrm{~S}=0.008, \mathrm{P}=0.005$. The material had mainly a tempered bainitic microstructure with isolated ferritic islands. Inclusions are mainly manganese sulfides. The tensile and CharpyV impact properties determined at various temperatures are given in Table 1.

Tests on axisymmetrically notched specimens were performed in the $\mathrm{T}$ orientation at various temperatures in the ductile-brittle transition range $\left(-150^{\circ} \mathrm{C}\right.$ and $\left.-30^{\circ} \mathrm{C}\right)$ to study the initiation of fracture. The dimensions of the specimens were : minimum diameter $\Phi_{0}=6 \mathrm{~mm}$; notch radius $=1.2 \mathrm{~mm}$ (AN 2-6) or $2.4 \mathrm{~mm}$ (AN 46 ) ; outer diameter $=10.8 \mathrm{~mm}$. These specimens were instrumented to measure the diametral contraction, $\Delta \Phi$. These tests were performed using a servohydraulic machine operating under displacement control 
with a ramp rate of $0.50 \mathrm{~mm} / \mathrm{mn}$. The average strain $\overline{\varepsilon_{f}}$ and stress $\overline{\sigma_{f}}$ at fracture were calculated as follows :

$$
\overline{\varepsilon_{f}}=2 \ln \left(\frac{\Phi_{o}}{\Phi_{f}}\right) \quad \overline{\sigma_{f}}=\frac{4 F_{f}}{\pi \Phi_{f}^{2}}
$$

Table 1 : Tensile and CharpyV impact properties.

\begin{tabular}{|c|c|c|c|c|c|}
\hline $\begin{array}{c}\text { Temp. } \\
\left({ }^{\circ} \mathrm{C}\right)\end{array}$ & $\begin{array}{c}\text { YS } \\
(\mathrm{MPa})\end{array}$ & $\begin{array}{c}\text { UTS } \\
(\mathrm{MPa})\end{array}$ & $\begin{array}{c}\mathrm{A} \\
(\%)\end{array}$ & $\begin{array}{c}\Sigma \\
(\%)\end{array}$ & $\begin{array}{c}\mathrm{K}_{\text {cv }} \\
\left(\mathrm{daJ}^{2} / \mathrm{cm}^{2}\right)\end{array}$ \\
\hline-150 & 762 & $\mathbf{8 8 2}$ & 28 & 56 & 0.5 \\
\hline-120 & 654 & 808 & 28 & 61 & 0.6 \\
\hline-90 & 604 & 768 & 29 & 64 & - \\
\hline-60 & 565 & 725 & 26 & 64 & 3.1 \\
\hline-30 & 547 & 701 & 26 & 67 & - \\
\hline 0 & 528 & 671 & 28 & 68 & 14.7 \\
\hline
\end{tabular}

Moreover fracture toughness experiments were carried out on CT 25 specimens tested in the TS orientation, over the same range of temperature to investigate the critical values of stable crack growth occurring before unstable cleavage. These specimens were instrumented to measure both the load-line displacement, $\delta$, and stable crack growth, $\Delta \mathrm{a}$, when it occurred prior to unstable cleavage fracture. Stable crack growth was measured using a potential drop technique and checked afterwards. These tests were performed using a servohydraulic machine operating under displacement control with a ramp rate of 0.25 $\mathrm{mm} / \mathrm{mn}$. Most of these tests were interpreted in terms of contour integral J. ASTM E 813-87 standards were used to calculate $\mathrm{J}$ and to account for the effect of eventual ductile crack growth on $\mathrm{J}$.

\section{EXPERIMENTAL RESULTS}

The tests on axisymmetrically notched specimens AN 2-6 and AN 4-6 were analysed by the Beremin or Weibull model with two parameters ( $\mathrm{m}$ and $\sigma_{\mathrm{u}}{ }^{\mathrm{m}} \mathrm{V}_{0}$ ). In this local approach, the probability to failure is written as [1] :

$$
P_{F}=1-\exp \left\{-\left(\frac{\sigma_{w}}{\sigma_{u}}\right)^{m}\right\}
$$

where $\sigma_{w}=\left[\int_{r z} \sigma_{1}{ }^{m} d V / V_{0}\right]^{\frac{1}{m}}$ is the Weibull stress. In this expression, $\sigma_{v}, V_{0}$ and $m$ are the characteristic parameters, $\sigma_{1}$ is the maximum principal stress acting in the volume element $\mathrm{V}_{0}$ while $\mathrm{PZ}$ is the volume plastically deformed.

35 AN 2-6 specimens were tested at $-150^{\circ} \mathrm{C}$ and 20 AN 4-6 specimens at $-90^{\circ} \mathrm{C}$. The results are represented in a $\ln \left\{\ln \left[1 /\left(1-\mathrm{P}_{\mathrm{F}}\right)\right]\right\}-\ln \left(\sigma_{\mathrm{W}}\right)$ diagram, in Fig. 1, assuming that $\mathrm{V}_{0}=(50 \mu \mathrm{m})^{3}$. It is observed a wide scatter in the results at $-150^{\circ} \mathrm{C}$ and at $-90^{\circ} \mathrm{C}$ but there are two populations of values : Weibull stresses calculated at $-150^{\circ} \mathrm{C}$ are more important than those obtained at $-90^{\circ} \mathrm{C}$. Moreover the scatter in the results at $-150^{\circ} \mathrm{C}$ is wider than that at $-90^{\circ} \mathrm{C}$ but it is noted that the number of specimens is larger at $-150^{\circ} \mathrm{C}$ than at $-90^{\circ} \mathrm{C}$.

All surfaces were examined by SEM. The fracture mode of specimens tested at $-150^{\circ} \mathrm{C}$ is essentially pure cleavage. The fracture mode of specimens tested at $-90^{\circ} \mathrm{C}$ is " mixed " : ductile fracture is observed close to the center while cleavage facets cover the remaining surface of the specimens. Examples of surface fracture are shown in Fig. 2.a and 2.b. The particles observed at the bottom of the ductile dimples were identified by $\mathrm{X}$-Rays spectrometry as manganese sulfide inclusions (MnS). 
A quantitative fractographic analysis was carried out on AN 4-6 specimens tested at $-90^{\circ} \mathrm{C}$ to determine the size and the location of « ductile zones ». On each AN 4-6 specimen, one ductile zone was identified from which cleavage fracture was initiated.

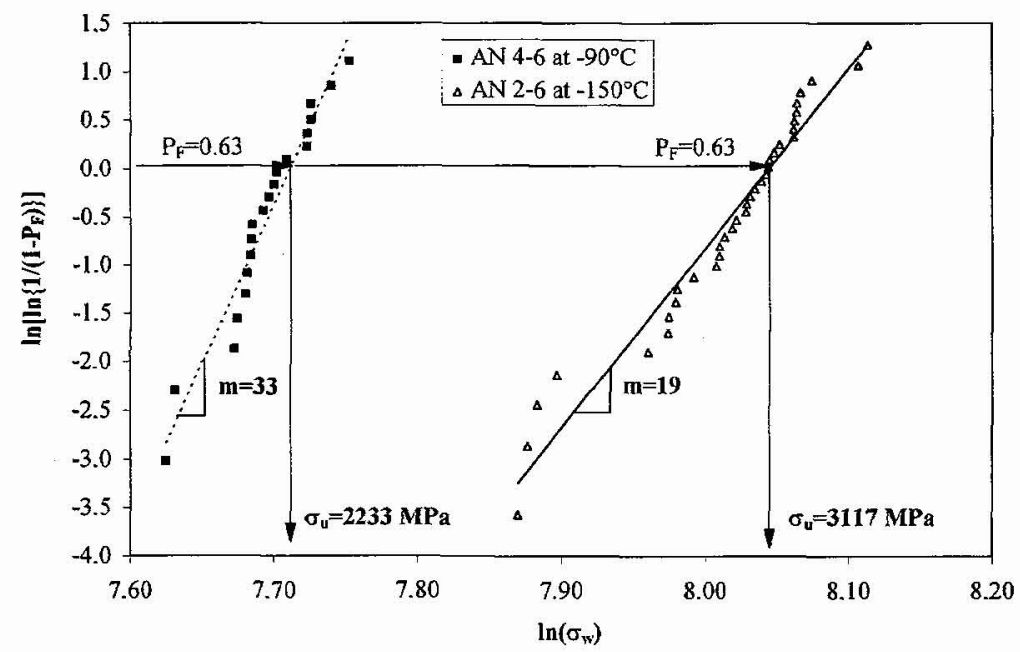

Figure 1: Curnulative probability to failure versus Weibull stress at $-150^{\circ} \mathrm{C}$ and at $-90^{\circ} \mathrm{C}$ in a Weibull diagram.

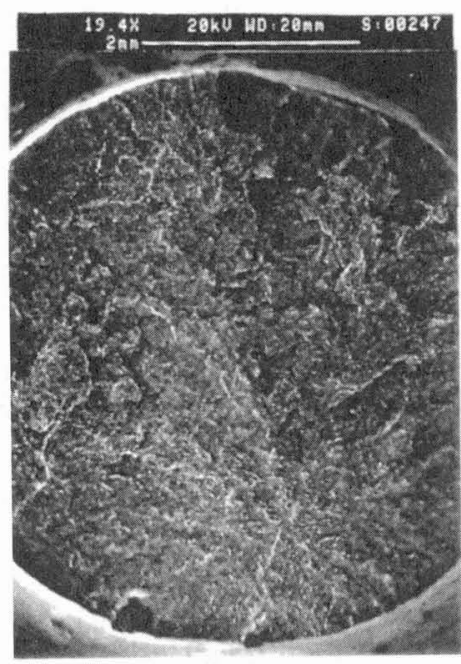

a/ AN $2-6$ at $-150^{\circ} \mathrm{C}$

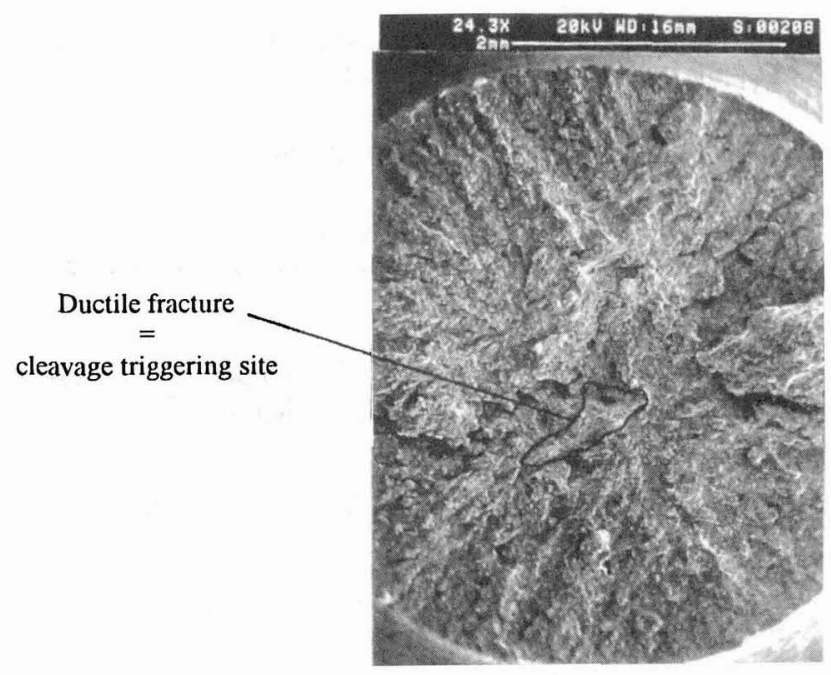

b/ AN $4-6$ at $-90^{\circ} \mathrm{C}$

Figure 2 : SEM micrographs illustrating the aspect of fracture surface of AN specimens tested.

These 20 ductile zones are characterized by large scatters of size and of location. Areas of ductile fracture were included between $0.044 \mathrm{~mm}^{2}$ and $0.652 \mathrm{~mm}^{2}$ (Fig. 3.a). However most of them are close to the average area which is equal to $0.313 \mathrm{~mm}^{2}$ (13 out of 20 are included between $0.200 \mathrm{~mm}^{2}$ and $0.400 \mathrm{~mm}^{2}$ ). The surface fraction of ductile fracture (which is the ratio of the ductile fracture area by the total fracture area) is not exceeding $4.0 \%$ and the average value is equal to $1.9 \%$.

The location of ductile zones is represented by a radial distribution across the minimum section where the distance is measured from the center of the specimen to the ductile zone. (Fig. 3.b). In this figure it is 
observed that ductile zones are not located exactly at the center of the specimen but at a distance varying between 0.1 and $1.2 \mathrm{~mm}$. More quantitatively 14 ductile zones $(70 \%)$ are located at a distance included between $0.5 \mathrm{~mm}$ and $0.9 \mathrm{~mm}$. The maximum frequency of the radial distribution is reached at $0.7 \mathrm{~mm}$ from the center of the specimen.
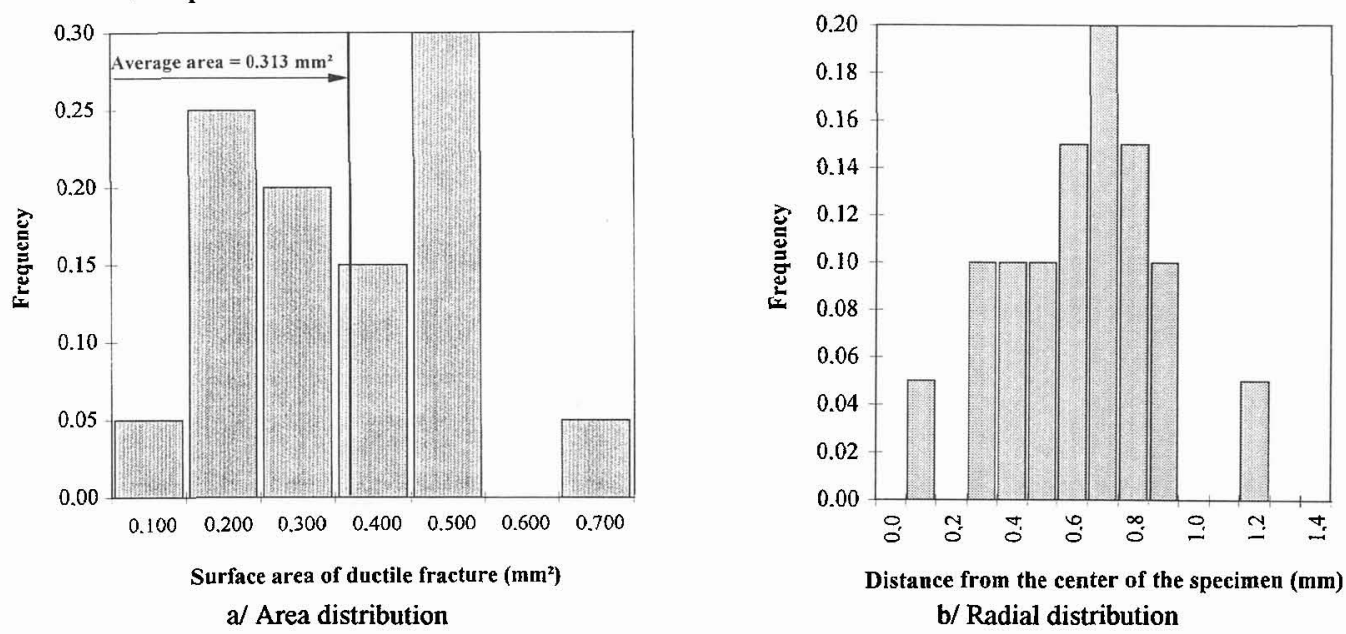

Figures 3 : Features of ductile zones observed on AN 4-6 specimens at $-90^{\circ} \mathrm{C}$.

These observations show therefore that the fracture mode on $\mathrm{AN}$ specimens is cleavage at $-150^{\circ} \mathrm{C}$ and at $90^{\circ} \mathrm{C}$ but the presence of small ductile zones observed at $-90^{\circ} \mathrm{C}$ could explain the difference in results shown in Fig. 1. Two assumptions, in agreement with these experimental observations, are made to explain this difference in behaviour on AN specimens :

$1 \%$ ductile fracture governs the fracture behaviour, at least at $-90^{\circ} \mathrm{C}$. In a small volume, when voids coalescence, ductile fracture creates a crack of critical size which triggers cleavage fracture of the whole specimen.

$2 \%$ ductile and cleavage fracture are in competition but are considered to be independant. For a small volume of material, one or the other fracture mode is initiated depending on the metallurgical and mechanical conditions.

These assumptions are tested after the presentation of results of fracture toughness tests.

The results of fracture toughness tests are shown in Fig. 4 where the values of ductile crack growth preceding brittle fracture are given. In this figure a large scatter in the results is observed especially around $0^{\circ} \mathrm{C}$ where large crack extensions prior to brittle fracture were observed. The scatter of fracture toughness with increasing temperature can be interpreted through an analytical expression between cumulative probability to failure $P_{F}$ and fracture toughness $K_{I C}$ which applies theoretically under small scale yielding conditions [1] :

$$
P_{F}=1-\exp \left[-\frac{K_{I C}^{4} \sigma_{0}^{m-4} B C_{m}(n)}{\sigma_{u}^{m} V_{0}}\right]
$$

where $B$ is the specimen thickness, $\sigma_{0}$, the yield strength at a given temperature and $C_{m}$, a numerical constant depending on the work hardening exponent, $n(\sigma=k \varepsilon)$.

In Fig. 4, we have drawn the results derived from Eq.4 (with $\mathrm{C}_{\mathrm{m}}=510^{3}$ ), using the values of $\sigma_{\mathrm{u}}, \mathrm{V}_{\mathrm{o}}$ and $\mathrm{m}$ which were determined on notched specimens $\mathrm{AN} 2-6$ at $-150^{\circ} \mathrm{C}$ (Fig. 1). In this figure we have also drawn the variation of the limit load with temperature. A good agreement between the theory and the 
experiments is observed, even above the limit load but only when cleavage is initiated without extensive ductile crack growth. When large crack extensions prior to brittle fracture were observed, Eq. 4 largely underestimates the observed fracture toughness for cleavage initiation. A model to predict the scatter of toughness fracture with large crack increments prior to brittle fracture is presented elsewhere [2]. The present work deals only with fracture initiation in the ductile-brittle transition regime.

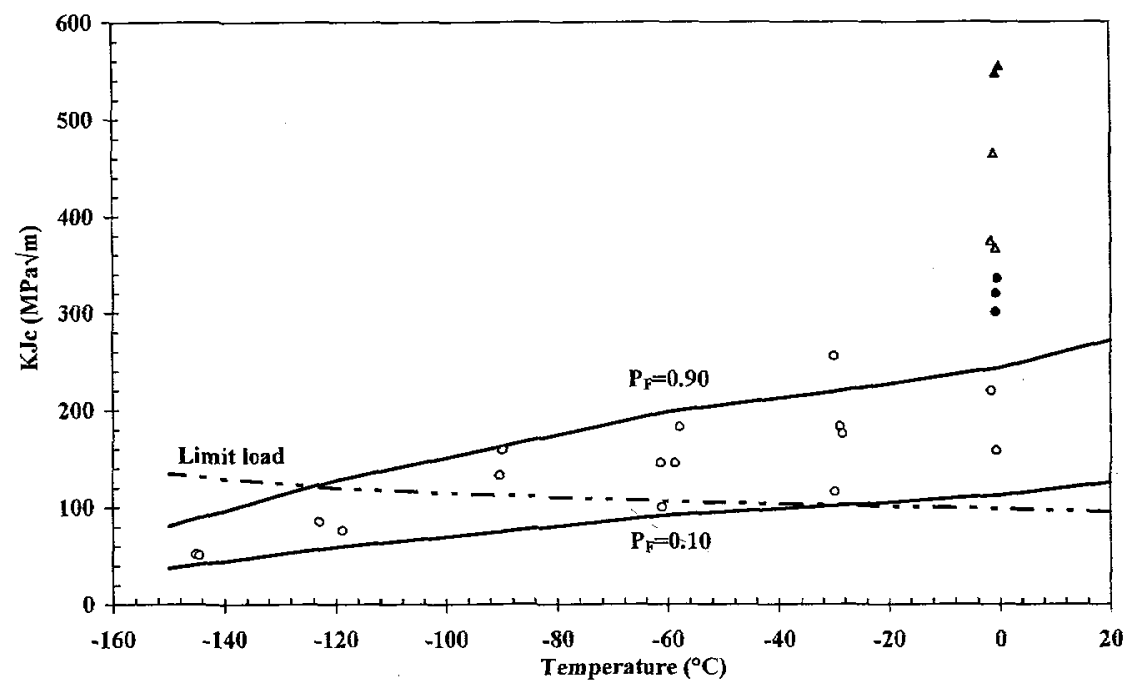

Figure 4 : Results of fracture toughness measurements with respect to crack extension $\Delta$ a before cleavage $(\triangle \Delta \mathrm{a}<0.5 \mathrm{~mm}, \bullet 0.5 \mathrm{~mm}<\Delta \mathrm{a}<1.5 \mathrm{~mm}, \Delta 1.5 \mathrm{~mm}<\Delta \mathrm{a}<3 \mathrm{~mm}, \Delta 3 \mathrm{~mm}<\Delta \mathrm{a}<6 \mathrm{~mm})$.

\section{MODELLING OF FRACTURE INITIATION}

An attempt is made to interpret the results obtained on axisymmetrically notched bars and on CT specimens in the ductile-brittle transition by a local approach. Probabilistic modelling is made by coupling the Beremin model [1] for cleavage crack initiation and a model derived from the Gurson potential [3] for ductile fracture initiation. In an elementary volume the probability for fracture depends on the probability for cleavage fracture and on the probability for ductile fracture. In a larger volume the probability for fracture is expressed in terms of elementary probabilities of fracture through the weakest link theory.

\subsection{Probabilistic modelling of ductile fracture}

If ductile damage controls the total fracture, the modelling of this damage must include probabilistic effect because of a wide scatter in the results.

The probabilistic modelling of ductile fracture initiation is based on a constitutive equation derived from the Gurson potential, on a distribution of $\mathrm{MnS}$ effective volume fraction in an elementary volume Vo and on the weakest link theory. The basis of this model was given in [4] and already used for a similar material to predict size effects on the ductility of notched specimens [5].

\section{Fracture criterion}

Ductile fracture initiates from particles like manganese sulfide inclusions. This fracture mode involves 3 stages which occur successively considering a volume element.

o Nucleation of voids occurs by inclusion-matrix decohesion or inclusion fracture under a critical stress 
$\left(\sigma_{d}\right)$. For our steel the value of this critical stress was determined by Mudry [4]. The nucleation stress $\left(\sigma_{\text {nucl }}\right)$ is expressed as :

$$
\sigma_{n u c l}=\sigma_{1}+\alpha\left(\sigma_{e q}-\sigma_{0}\right) \geq \sigma_{d}
$$

where $\sigma_{\mathrm{eq}}$ is the von Mises equivalent stress, $\sigma_{0}$ the yield stress and $\alpha$ a constant which is function of the particle shape.

o Growth of voids depends on the stress triaxiality $\left(\sigma_{m} / \sigma_{y}\right)$ and on the increment of equivalent plastic strain $\left(\mathrm{d} \varepsilon_{e q}\right)$. Voids growth function in a porous material is derived from the Gurson yield function $\Phi$ assuming the matrix incompressibility. In the case of spherical voids, with a volume fraction $f$, the Gurson yield function is given by [3] :

$$
\Phi=\frac{\sigma_{e q}{ }^{2}}{\sigma_{y}{ }^{2}}+2 f \cdot q_{1} \cdot \cosh \left[q_{2} \cdot \frac{\sigma_{m}}{\sigma_{y}}\right]-\left[1+\left(q_{1} f\right)^{2}\right]=0
$$

where $\sigma_{\mathrm{eq}}=\sqrt{\frac{3}{2} \mathrm{~s}_{\mathrm{ij}} \mathrm{s}_{\mathrm{ij}}}$ is the equivalent stress in the porous material associated to the equivalent plastic strain $\varepsilon_{\mathrm{eq}}{ }^{\mathrm{p}}, \mathrm{s}_{\mathrm{ij}}$ are the components of the stress deviator, $\sigma_{\mathrm{m}}=1 / 3 \Sigma_{\mathrm{i}} \sigma_{\mathrm{ii}}$ is the hydrostatic stress and $\sigma_{\mathrm{y}}$ is the flow stress in the matrix material, $\sigma_{y}=k \cdot\left(\varepsilon_{e q}^{p}\right)^{n}$.

The parameters $q_{1}$ and $q_{2}$ were introduced by Tvergaard [6] to bring the predictions from the Gurson model at low volume fractions into closer agreement with full numerical analysis of arrays of voids. The numerical values of these parameters are $: q_{1}=1.50 ; q_{2}=1.50$.

The yield function and the assumption of incompressibility can be used to determine the evolution of the volume fraction of cavities :

$$
\begin{aligned}
& f\left(\varepsilon_{e q}^{p}\right)=f_{0} \cdot e^{I} \\
& \text { where } I=\left\{\int_{\varepsilon_{e q}^{p}}^{\varepsilon_{e q}^{p}}\left[\frac{3}{2} \sinh \left(\frac{3}{2} \frac{\sigma_{m}}{\sigma_{y}}\left(\varepsilon_{e q}^{p}\right)\right)\right] d \varepsilon_{e q}^{p}\right\}
\end{aligned}
$$

with $\varepsilon_{e q_{n u c l}}^{p}$ is the equivalent plastic strain for void nucleation in the volume element and $f_{0}$, the initial effective volume fraction of voids which is taken equal to the effective volume fraction of inclusions.

o Coalescence of voids is the last stage of ductile fracture initiation. It is assumed that this last stage occurs for a critical value of volume fraction of voids.

For low volume fractions $\left(\mathbf{f}<10^{-3}\right)$, the equivalent stress in the porous material can be expressed as :

$$
\sigma_{e q}=\sigma_{y} \cdot \sqrt{1-2 \cdot f \cdot q_{1} \cdot \cosh \left[q_{2} \cdot \frac{\sigma_{m}}{\sigma_{y}}\right]}
$$

Assuming that fracture occurs in the elementary volume Vo when the equivalent stress reaches its maximum, a critical volume fraction $f^{f}$ is calculated $[4,7]$. Then the void growth function determined from flow behaviour of porous material is used to calculate the critical initial void volume fraction $f^{c}$. Thus, in a homogeneous material, fracture of an elementary volume Vo submitted to an equivalent plastic strain $\varepsilon_{\mathrm{eq}}{ }^{\mathrm{p}}$ occurs if the initial void volume fraction, fo, is larger than a critical value, fo ${ }^{c}$. In the following, fo is identified as the $\mathrm{MnS}$ effective volume fraction.

\section{Elementary Probability}

In an heterogeneous material, the elementary probability to failure, $p_{f}\left(V_{0}, \varepsilon_{e q}{ }^{p}\right)$, can be defined in a volume element Vo, for a given loading through the distribution of the inclusions. The probability to failure $p_{f}($ Vo, 
$\varepsilon_{\mathrm{eq}}^{\mathrm{p}}$ ), is the probability of finding an initial void volume fraction, fo, larger than the critical value, fo ${ }^{\mathrm{c}}$. This probability was calculated with the distribution function of the inclusion effective volume fraction $F$ which was determined experimentally by image analysis :

$$
p_{f}\left(V o, \varepsilon_{e q}^{p}\right)=p\left[f_{o} \geq f_{o}^{c}\left(\varepsilon_{e q}^{p}\right)\right]=1-F\left[f_{o}^{c}\left(\varepsilon_{e q}^{p}\right)\right]
$$

$F$ is a log-normal function. The elementary volume $V o$ associated to the distribution function $F$ is depending on the elementary observation surface So used in the inclusion analysis : $\mathrm{Vo}=\mathrm{So}^{3 / 2}$. The values of distribution parameters and the value of the average of the $\mathrm{MnS}$ effective volume fraction in $\mathrm{T}$ orientation are given in Table 2 .

\section{Cumulative probability to failure}

The cumulative probability to failure $P_{F}$ of the specimen with a fracture volume $V_{\text {nucl }}$ is calculated from the elementary probabilities $\mathrm{p}_{\mathrm{f}}\left(\mathrm{Vo}, \varepsilon_{\mathrm{eq}}{ }^{\mathrm{p}}\right)$ through the weakest link theory. $\mathrm{V}_{\text {nucl }}$ is determined by a critical nucleation stress $\left(\sigma_{\text {nucl }}\right)$ defined by eq. 6 .

If $V_{\text {nucl }}$ is very large compared to Vo: $P_{F}=1-\exp \left\{\int_{V_{\text {nucl }}} \frac{\ln \left[F\left(f o^{c}\right)\right]}{V o} d V\right\}$

The result of this probabilistic approach of ductile fracture initiation is a cumulative probability to failure associated to a loading parameter as the plastic strain $\varepsilon_{\mathrm{eq}}^{\mathrm{p}}$. All the parameters used in this probabilistic ductile fracture model are given in Table 2 .

\subsection{Probabilistic modelling of ductile-brittle fracture}

In this approach of ductile-brittle transition modelling, fracture takes place if one of the two fracture modes is initiated. Both fracture modes are assumed to be competing without interaction.

\section{Elementary probability}

In a volume element $\mathrm{Vo}$, the probability for fracture $\mathrm{p}_{\mathrm{f}}(\mathrm{Vo})$ by cleavage or by ductile tearing is function of the probability for ductile fracture $p_{f d}$ associated to a elementary ductile volume $\left(\mathrm{Vo}_{d}\right)$ and of the probability for cleavage fracture $\mathrm{p}_{\mathrm{fe}}$ associated to a elementary cleavage volume $\left(\mathrm{Vo}_{\mathrm{c}}\right)$. Due to the assumption of competition of both fracture modes without interaction in a elementary volume and the statistical independence of elementary volumes, the probability for fracture $p_{f}(\mathrm{Vo})$ is expressed as :

$$
1-p_{f}(V o)=\prod_{V o_{d} \in V o}\left[1-p_{f d}\left(V o_{d}\right)\right] \prod_{V o_{c} \in V o}\left[1-p_{f c}\left(V o_{c}\right)\right]
$$

\section{Cumulative probability to failure}

The cumulative probability to failure $P_{F}$ of the specimen is calculated from the elementary probabilities $\mathrm{p}_{\mathrm{f}}(\mathrm{Vo})$ through the weakest link theory. Then the cumulative probability for bimodal fracture is given by :

$$
P_{F}=1-\exp \left\{\int_{V_{\text {mucl }}} \frac{\ln \left[F\left(f o^{c}\right)\right]}{V o_{d}} d V\right\} \exp \left\{-\left(\frac{\sigma_{w}}{\sigma_{u}}\right)^{m}\right\}
$$

The results of mechanical tests on AN 2-6 specimens were used to determine the characteristic parameters describing brittle fracture in the model (Table 2). 
Table $2 \because$ Data of ductile-brittle fracture probabilistic modelling.

\begin{tabular}{|c|c|c|c|c|c|c|c|c|}
\hline \multicolumn{6}{|c|}{ Probabilistic modelling of ductile fracture } & \multicolumn{3}{|c|}{ Modelling of brittle fracture } \\
\hline \multicolumn{3}{|c|}{$\begin{array}{c}\text { inclusion distribution } \\
\text { parameters }\end{array}$} & \multicolumn{2}{|c|}{$\begin{array}{l}\text { Nucleation } \\
\text { criterion }\end{array}$} & \multirow{2}{*}{$\begin{array}{c}\begin{array}{c}\text { element. } \\
\text { volume }\end{array} \\
\mathrm{V}_{0}\left(\mathrm{~mm}^{3}\right)\end{array}$} & \multicolumn{2}{|c|}{$\begin{array}{c}\text { Weibull } \\
\text { parameters }\end{array}$} & \multirow{2}{*}{$\begin{array}{c}\text { element. } \\
\text { volume }\end{array}$} \\
\hline$\overline{\mathrm{f}_{0}}$ & a : average & $\begin{array}{l}\text { s : standard } \\
\text { deviation }\end{array}$ & $\begin{array}{c}\sigma_{\mathrm{d}} \\
(\mathrm{MPa})\end{array}$ & $\alpha$ & & $\mathbf{m}$ & $\begin{array}{c}\sigma_{\mathrm{u}} \\
(\mathrm{MPa})\end{array}$ & \\
\hline $9.4 e-4$ & -0.69 & 1.14 & 1120 & 1.6 & 0.100 & 19 & 3117 & $1.25 \mathrm{e}-4$ \\
\hline
\end{tabular}

\subsection{Application to AN specimens}

The preceding model was applied to derive the local probabilities for bimodal, ductile and cleavage fractures across the minimum section of AN specimens (Fig. 5). An effect of tested volume is observed: the highest local probability for ductile, cleavage and bimodal fracture are not found at the specimen center where stress triaxiality and maximum principal stress are maximum but at about $0.75 \mathrm{~mm}$ from the center where the combination of stress triaxiality and tested volume is the more favourable for both modes of fracture. These results are in agreement with the radial distribution of fracture initiation sites determined on AN 4-6 specimens broken at $-90^{\circ} \mathrm{C}$ (Fig 3.b).

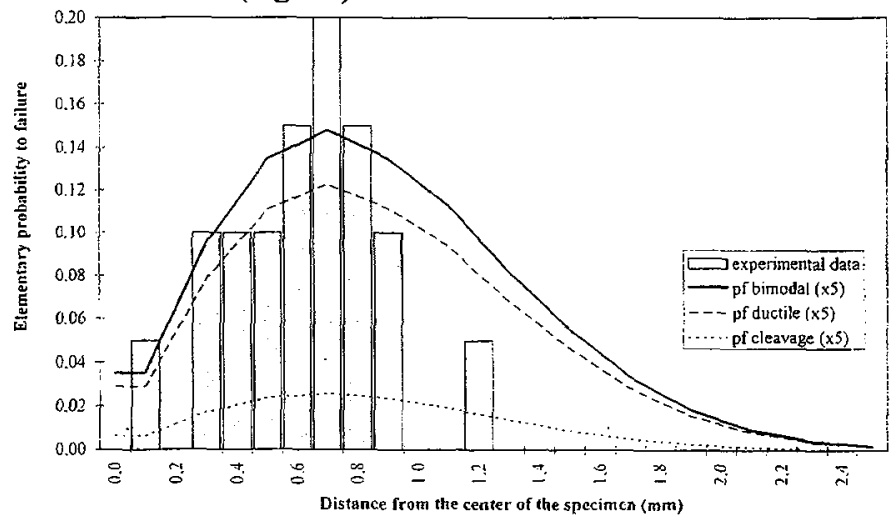

Fig. 5 : Elementary probabilities for fracture and frequency of ductile zones across the minimum section on $\mathrm{AN} 4-6$ at $-90^{\circ} \mathrm{C}$.

Assuming that ductile fracture of a small volume $\mathrm{Vo}_{\mathrm{d}}$ leads to total failure (by cleavage) of the specimen, this model can also be used to determine the cumulative probability for bimodal fracture (Fig. 6). In this figure a good agreement between the model and the experiments is observed. In particular it is observed that cleavage controls the fracture mode at $-150^{\circ} \mathrm{C}$ while ductile fracture is prevailing at $-90^{\circ} \mathrm{C}$.

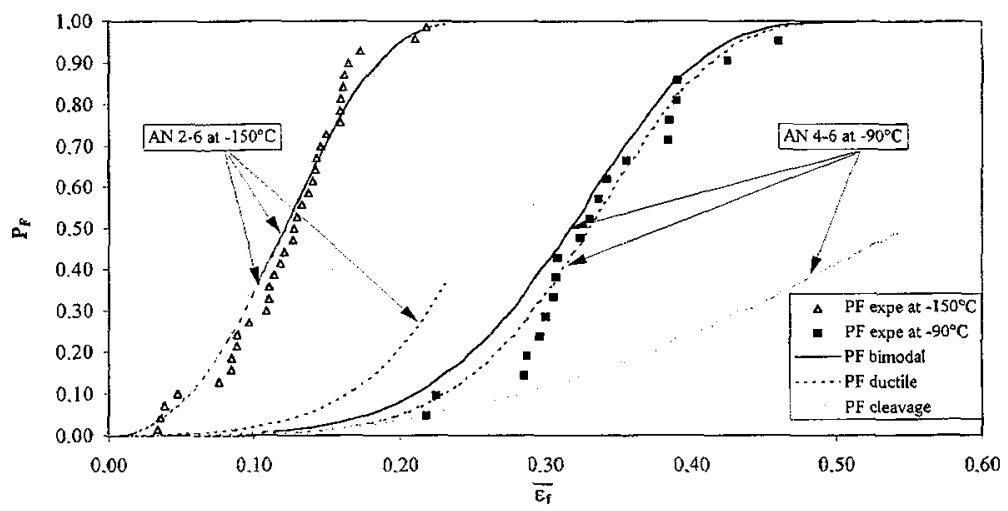

Figure 6 : Calculated and experimental cumulative probabilities for fracture versus fracture average strain on AN 2-6 at $150^{\circ} \mathrm{C}$ and on $\mathrm{AN} 4-6$ at $-90^{\circ} \mathrm{C}$. 


\subsection{Application to CT specimens}

Probabilistic modelling of ductile-brittle fracture is applied to CT25 specimens from $-150^{\circ} \mathrm{C}$ up $0^{\circ} \mathrm{C}$. It is noted that the above model predicts only fracture initiation, so it is not able to take account ductile crack preceding cleavage fracture, in particular at $0^{\circ} \mathrm{C}$. Therefore our model is only able to predict if ductile fracture will be initiated or if cleavage fracture will be triggered with no ductile extension. Above the limit load, it is necessary to use finite elements calculations to determine the probabilities for cleavage and for ductile failures for a given value of $J$ parameter. Fine meshes $(3 \mu \mathrm{m}$ at the crack tip) and initial crack blunting are used to obtain a good estimate of the crack tip stress-strain field. More details can be found elsewhere [8]. The application of the model to the non side groved CT specimens used in our study needs theoretically full 3D calculations. However an estimate of the failure initiation of the CT specimens can be achieved using a combination of $2 \mathrm{D}$ (i.e. plane stress, $\mathrm{P} \sigma$, and plane strain, $\mathrm{P} \varepsilon$ ) numerical computations. The $\mathrm{J}$ values were supposed to be a linear combination of $\mathrm{J}_{\mathrm{P} \sigma}$ and $\mathrm{J}_{\mathrm{P \varepsilon}}$ :

$$
J=\frac{B_{P \sigma}}{B} J_{P \sigma}+\frac{B_{P \varepsilon}}{B} J_{P \varepsilon}
$$

where $\mathrm{BP \sigma}$ and $\mathrm{BP \varepsilon}$ are the part of the thickness under plane stress and plane strain, respectively. At $0^{\circ} \mathrm{C}$, the calculated and experimental $J$ versus crack opening curves were found to be similar if $\mathrm{BP \sigma}=22 \mathrm{~mm}$ and $\mathrm{BP \varepsilon}=3 \mathrm{~mm}$. These values of $\mathrm{BP \sigma}$ and $\mathrm{BP \varepsilon}$ were used to calculate, over all the temperature range investigated, the probability for bimodal fracture $P_{F}$ which depends on the probability for cleavage fracture $P_{\mathrm{Fc}}$ and on the probability for ductile fracture initiation $P_{\mathrm{Fd}}$ as :

$$
P_{F}=1-\left(1-P_{F d, P \sigma}^{\prime}\right)^{B_{P \sigma}} \cdot\left(1-P_{F d, P \varepsilon}^{\prime}\right)^{B_{P_{\varepsilon}}} \cdot\left(1-P_{F c, P \sigma}^{\prime}\right)^{B_{P \sigma}} \cdot\left(1-P_{F c, P \varepsilon}^{\prime}\right)^{B_{P \varepsilon}}
$$

where $\mathrm{P}_{\mathrm{Fd}}^{\prime}\left(\mathrm{P}_{\mathrm{Fc}}\right)$ is the probability for ductile (cleavage) fracture for a specimen of unit thickness.

The experimental values of fracture toughness for cleavage initiation, with a ductile crack extension less than $0.5 \mathrm{~mm}$ are compared with calculated fracture initiation curves which are defined for a cumulative probability for fracture equal to 0.20 in Fig. 7. In this figure it is observed that the calculated bimodal fracture initiation curve corresponds to the lower bound of the experimental values. Moreover our model shows that cleavage fracture is the more probable mode at $-150^{\circ} \mathrm{C}$ and that ductile fracture initiation is the more probable mode at $0^{\circ} \mathrm{C}$. These results which are in agreement with the experimental examinations, indicate that, for the lower bound of the toughness, the transition regime is the consequence of the competition between cleavage and ductile damages.

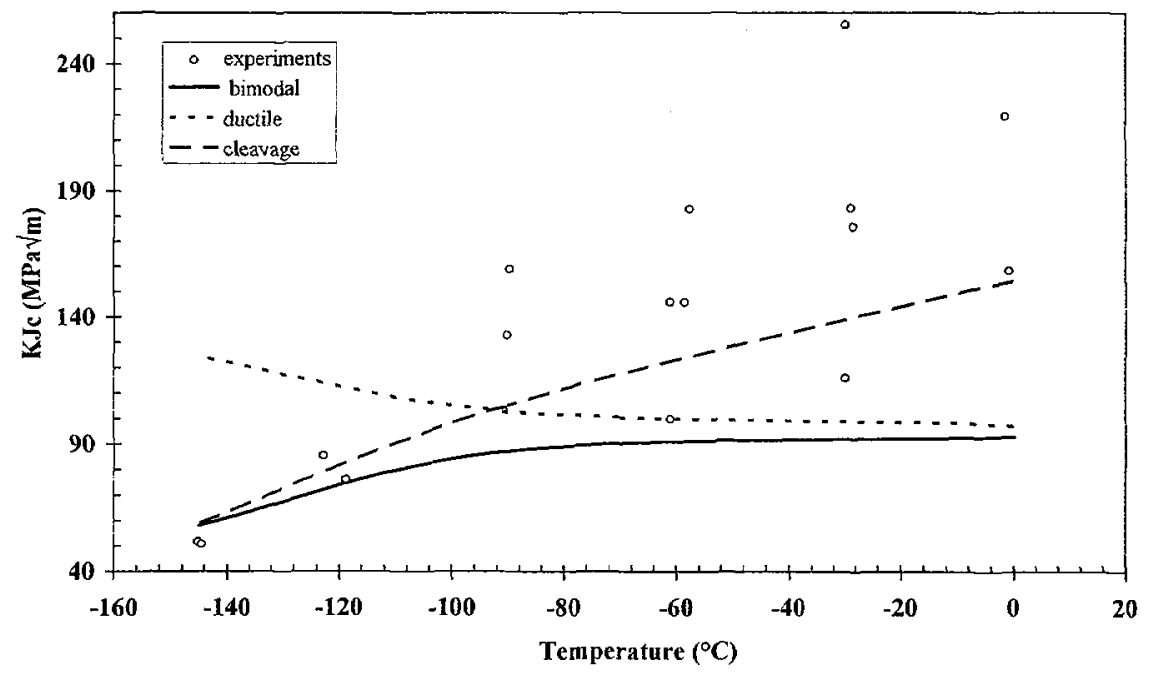

Figure 7 : experimental fracture toughness for cleavage initiation without ductile crack growth and calculated values with increasing temperature. 


\section{CONCLUSIONS}

The behaviour in the transition regime of a low alloy ferritic steel was studied on axisymmetrically notched (AN) bars and on compact tension (CT) specimens.

Modelling of the initiation of ductile-brittle fracture has been performed using the weakest link theory and the assumption of a competition between ductile and cleavage damages ; both having a probabilistic expression. As expected, for a given strength (ductility or toughness), it is shown that the probabilities of cleavage and ductile fracture are respectively increasing and decreasing function of the temperature.

Cleavage damage is described using the Beremin model and appears to be strictly valid at low temperature (here $-150^{\circ} \mathrm{C}$ ). However it is confirmed that the analytical expression derived from the theory of brittle fracture valid for small scale yielding (Eq. 4) describes correctly the variation $\mathrm{K}_{\mathrm{IC}}$ with temperature in the absence of significant ductile crack growth. This expression applies also to some extent above the limit load.

Ductile fracture initiation is modelled with the use of the mechanics of porous materials. Statistical aspects are also introduced with the distribution of the volume fraction of inclusions. This model, in agreement with the quantitative fractographic measurements, shows that a small amount of ductile damage (less than $4 \%$ in surface) can control the fracture of a volume element like the AN specimens tested at $-90^{\circ} \mathrm{C}$.

The model applied to cracked specimens shows that the lower bound of the fracture toughness with temperature measured on CT specimens is the consequence of the competition between cleavage and ductile damages at initiation.

\section{References}

[1] Beremin F.M., Met. Trans. A. 14A (1983) 2277-2287.

[2] Renevey S., Carassou S., Marini B., Eripret C. and Pineau A. 'Statistical modelling of the ductilebrittle transition of ferritic steels" Proceeding of ECF11, Poitiers (France), 3-6 September 1996.

[3] Gurson A. L., J. of Eng. Mat. and Tech. Trans. ASME 99 (1977) 2-15.

[4] Mudry F., Thèse de Doctorat es Sciences Université de Technologie de Compiègne (1982).

[5] Carassou S. Marini B., 'Effet d'echelle en rupture ductile sur un acier type A48" Proceeding of Journées d'Automne de la SF2M, Paris (France), 18-20 November 1994.

[6] Tvergaard V., Int. J. of Fract. 17 (1981) 389-407.

[7] Berg C.A., Inelastic behavior of solids (Editors Kanninen M. K. et al, Mc Graw Hill, 1969) pp. 171209.

[8] Di Fant M., "Development of a simplified approach for using the local approach to fracture" Proceeding of MECAMAT'96, Moret (France), 9-11 September 1996. 